\title{
On the Philosophical Possibilities of a Constructive Theology of Self
}

\author{
By Paul T. Lewis*
}

\begin{abstract}
I shall be arguing that the most appropriate way to conceive of the self within a constructive theology is as a material spirit. The force of the argument depends on establishing the necessity of a number of interrelated conditions, e.g., psychological, sociological, linguistic, biological and historical, for the dual arising of self and soul. The argument is essentially divided into four parts, bordered by a prologue and an epilogue. After brief allusions to both modernity and postmodernity conceptions of self, the prologue moves on to definitions and caveats. The first two parts are concerned with the self-hermeneutics of modernity and post-modernity including a postmodern critique of modernity. The third proposes a way beyond these two hermeneutics without sacrificing the virtues of either, through what I call a "Subsumtive" Philosophy. Finally, in the fourth part a meditation demonstrates how raw self provides a mind and body interactive context for the emergence of metaphor, the arising of self as material spirit, and further development of both self and soul. The epilogue clarifies additional philosophical possibilities of this constructive theology of self by critically focusing on the soul, conceptual clarity, along with ontogenetic, ontological, and epistemological issues.
\end{abstract}

\section{Prologue}

The self may not be constructed at all. Unencumbered by the expectations of its erstwhile author, the self may lie dormant, its potential unrealized. Bereft in a sea of uncertainty it may yield no fortune for its host, however outrageous, if such a host fails to lift a hand to the narrative sheet upon and through which the fate of the self depends, as a post-modern philosophy of self might claim. Indeed, such a fate may remain unrealized for potential selves resident in persons afflicted with autism, who fail to construct a theory of mind, a necessary condition for the emergence and development of the internalized other, much less the self. In other disorders, like schizophrenia, persons may have had the good fortune to construct a self initially, only to have it severely compromised by the ravages of the disease process. As a modern philosophy of self might assert, either of these disorders suggest that a healthy functioning

${ }^{*}$ Professor, Bethel College,USA. 
brain and nervous system is a necessary condition for the arising and maintenance of self.

Following the theologian, Gordon Kaufman (1993, 2004), a constructive theology acknowledges at the outset its being a human product, a product that changes with the times, whether those times are biological, psychological, social, linguistic, political, historical, theological, and so on. It is a product that most benefits from the give and take of a community united under a symbol of transcendence, and among whose members represent the various scholarly disciplines, but can be developed and refined by persons living outside that community as well, who do not necessarily represent academia.

A couple of caveats before I begin: while this paper will not incorporate scriptural sources per se, it will draw on traditional and contemporary philosophy works, along with social and behavioral science research, given the desire for a constructive theology of self that is broadly applicable. It will also not address the standard questions found in the philosophy of religion literature, e.g. theodicy, divine intervention, double agency, etc., for the simple reason to avoid obfuscating its principal focus - bringing together theology and self.

\section{Part I: Self in Modernity}

Starting off are the early modern psychoanalytic hermeneutics of Freud ([1923] 1960) and Jung (1957) that have traditionally emphasized the inference of a self-structure internal to the person, composed of both conscious and unconscious elements. The individual is privileged over society, especially by Freud by emphasizing evil (i.e., self interest) over good (following Hobbs?) Both embrace a universalistic monism, but with Freud focusing on Eros, and Jung on the Analytic Self.

Later mid-modernity self hermeneutics are the existential psychological theories of Carl Rogers (1956) and Abraham Maslow (1968), which emphasized even more the individual over society through the experiential states of freedom of choice and willful control of action. Society needs to either allow and help the individual to express his/her innate goodness through unconditional positive regard, or get out of the way (following Rousseau?). As a result the individual develops an 'Authentic Self.' The self as Self-Actualized is the monistic focus.

Both of these more clinically oriented self hermeneutics have been superceded by a late modernity cognitively based theory more conducive to scientific study. These are the hermeneutics of social psychologists' Swann's (1983) self-verification bias, and Marcus and Nurius' (1986) possible selves, which have revealed both the resiliency and changeability respectively, of the self concept depending on individual and/or societal concerns. The cognitive self has a discernible structure, process, and content more congenial to empirical study than the psychoanalytic, analytic, or existential selves of the preceding self-hermeneutics. A pluralistic treatment of the cognitive presides. 
However, where the cognitive self goes, the cognitive other must follow, given the way each necessarily makes the other up. The sociologist George Herbert Mead (1934) argued that a self consciously aware of itself was dependent on its taking itself as an object. To take the self as an object a vantage point is needed, e.g., the generalized other, an internalized representation of society. The existence of self is thus dependent on society. This is not to suggest, however, their being synonymous; rather, whatever is unique to self is unique only in relation to society.

\section{Implications}

There are important modernity elements that contribute much to the present theology, e.g., the significance of internality of the self, as well as the apprehension of the cognitive element of the self through scientific means. However, the overwhelming presumption of fully understanding the essential structure, or process, or content of the self quite apart from the community of discourse within which it is embedded, with the exception of Mead, of course, is troublesome.

\section{Part II: Self in Post-Modernity}

The principal critique of modernity self hermeneutics is based in the impossibility of ever perceiving the world as it really is outside the constructs of language. In his Philosophical Investigations, Wittgenstein posited that in the very act of naming something, we immediately enter the world of language through which we perceive the world of phenomena. Our understanding of ourselves, then may be as much infused with language as our understanding of the world and in its pure state as forever hidden from our minds. The noted deconstructionist philosopher Derrida (1978) also makes a persuasive case for the world we confront being wholly and inevitably immersed in language.

Acknowledging the essential interconnected nature of word and world brings along with it a new conception of the self writing its own text, or self as narrative. Post-modernity scholars believe that texts written by the self do not refer to obdurate realities 'in there,' like most modernists might posit, but other texts. For example, if we had the luxury of writing down our immediate experience as it occurred we could still not eschew putting names on some parts and not others, and using some names but not others for the experiences we chose to name. Moreover, in those reflective moments when we think back on our earlier named textualized experience, we write another text. No lives are separate from the medium of language through which self-texts (or narratives), are written and read, and as social constructivist Kenneth Gergen (1988) suggests, there is no more valid narrative about a self's life than a narrative written by that self. The post-modernity self thus assumes a privileged epistemological position in its own understanding.

This privileged epistemological status of self as narrative and its everchanging discourse context make it uncongenial to traditional scientific 
positivistic notions of truth. The well-acknowledged bias of recollection, the basis of self-narrative, and the multifaceted structure of narrative itself makes obtaining an objective and incontrovertible truth a daunting task. Consequently, Gergen (1988) has spoken of 'narrative truth' being a special kind (cf. Coherence Theory of Truth) distinct from historical or traditional scientific truth (cf. Correspondence Theory of Truth). For example, each new element of a person's life, like marriage, or graduation, achieves currency only within a present narrative structure underwritten by a theme promoting an acceptable narrative objective. Derrida (1978) advocates 'de-substantializing' the self, arguing to not regard it as bounded but as boundary-less, thus requiring it be put squarely within discourse, where it rightly belongs. Gergen (1988) and socio-materialist Daniel Dennett (1991) believe that as a consequence, self will be seen not as the source of, but instead as embedded in meaning and thus as destination to our discursive efforts.

Proponents of self as narrative have been able to show how traditional conundrums in the psychology of self can be re-described and therapeutic advances made for the troubled self. As personality theorist Dan McAdams has discovered (1997), self as narrative allows us to newly understand construction and maintenance of self-identity, underwritten by narrative tone and theme stretching throughout one's life story. Clinical psychologist and philosopher Paul and John Lysaker respectively, have shown (2008) how self can transcend delimiting biological and social conditions through a liberating dialogic discourse made up of opposing meta-positions. Indeed, postmodern therapists Parry and Doan (1994) clarify how 'Editor therapists' help 'Author patients' to deconstruct old problematic stories, constructing in their place new stories more conducive to realizing the Author's life-aims, turning the self from a life of despair to one of hope.

\section{Implications}

The postmodern self hermeneutic is helpful for the present theology insofar as it emphasizes that the self has almost unlimited freedom in what it constructs about itself, that there may be as many viable lives as there are viable selves, that no one self narrative insists as definitive. By giving precedence to differences as opposed to similarities across narratives within community, the possibility of theological development is increased. However, the self as only narrative creates problems of its own.

\section{Part III: Beyond Post-Modernity Critiques and Recommendations}

That there are times that the other knows the self better than the self should make one question its epistemological privilege. It appears self-evident, despite erudite protestations to the contrary (cf. Mill's Essay on Liberty), that when either the integrity of self-consciousness breaks down or we do something out of character, that we appeal to the good counsel of others regarding who we really are or have become. This lack of epistemological privilege is quite 
apparent in Dissociative Identity Disorder (DID) (cf. Comer, 2013). One of the intellectual curiosities of DID is the absence of an executive self which functions to control with conscious awareness the ascendant and descendent sub-selves as the occasion may warrant. Thus, therapist may know self better than self, insofar as the self to be known is really several selves together having limited knowledge of each other. This breakdown of epistemological privilege also happens in schizophrenia (cf. Lysaker \& Lysaker, 2008) and autism (cf. Comer, 2013). This work suggests that whatever self is, it is more than it knows, e.g., brain based necessary conditions unconsciously affecting it.

That self-narrative and its underlying neurological basis have been studied scientifically should give us pause that science is inappropriate to study the self. Adult developmentalist and psychoanalyst Bertram Cohler (1983) documented scientifically the importance of a narrative perspective on how persons integrate self-inconsistent information at significant developmental turning points. McAdams (1997) showed scientifically how narrative tone and theme shapes development of a narrative influencing the choices that self has. Neuroscientist Antonio Damasio (1994) analyzed the brains of frontal lobe damaged patients having difficulty making decisions about personal and social matters. He provided evidence for the affected area being the ventral medial area of the prefrontal cortex. Neuropsychologists Kircher and David (2003) affirmed this and other brain areas underlying healthy and unhealthy self functioning.

The Subsumtive Philosophy featured herein is congenial to taking serious account of biologically-based necessary conditions. However, at the same time it recognizes the insufficiency of biological factors: language is crucial.

However, that the world cannot be studied separately from the language used to understand it obscures important distinctions between science and other interpretive systems. Certainly science is a language; however, it is a language developed for clarifying what is the case, apart from the way the case is measured. The efficacy of science depends on controlling interpretive biases. This is accomplished by a consensus-mediated objectivity achieved through a set of rules for making observations having a firm basis in sense-impression (cf. Hume's Essay on Human Understanding). If two people independently apply a set of sense-impression based rules for determining a phenomenon's existence, and agree, then for all intensive purposes that phenomenon exists. If the phenomenon categorized is a self, then such an entity's ontology adds a quality of subjectively experienced sensations and reflections.

Despite the reluctance of post-modernity scholars to embrace the possibility of there being a self universal, by comparing the results of narrative, cognitive, and neurological based studies systematically one to the other (cf. Fiske, 1971), one could discover self universals in the area of interpretative overlap, whether more sensation or reflection based: an ontological universal may be the ongoing experience of sensation tied to its underlying neurological signature, while an epistemic universal may be a trans-cultural first-order reflective description, e.g., the emotional inference of pleasure given a face reflecting a Duchenne smile. 
In addition, the disavowal of self as source for action possibly distinct from self as destination of that very action needs to be reexamined. One difficulty of self as narrative destination as opposed to narrative source is question begging: Can the source of our narratives be something other than ourselves? Daniel Dennett believes evidence suggests, paradoxically, that we tell who we are through the spinning of narratives, but they spin us, we do not spin them. Dennett further argues that whoever we end up being, we are the 'center of narrative gravity (1991, p. 418),' a product of both our brains and the socio-cultural surround. Thus, we only seem to take possession of our narratives post-hoc, reminiscent of the famous Nietzsche observation, 'A thought comes when it wishes, not when I wish' (cf. Beyond Good and Evil). Sure - some do, but certainly not all, as simple thought experiments will attest.

While presupposing material, social and discursive bases to the self, the current theology also posits sources of will and choice that confer a uniqueness of consciousness, but not just the split between self and object, which consciousness itself presupposes, but the split between self as subject and self as object, as self-consciousness presupposes (cf. Hegel's 'Being for itself,' in his Phenomenology of Spirit). These sources of consciousness serve as means to a variety of ends, in both physical and metaphysical worlds, e.g., the self choosing to build a house, or to discover itself, or to reinvent itself. Might self be not only destination, but source as well? If that destination is eternal life, or some otherworldly end, it would be hard to argue for the causes of such a destination being outside self completely; but also hard to argue that self alone is up to such a task.

The concept of soul not only helps achieve everyday life rhetorical purposes, but also has much philosophical precedent. Rhetorically, popular culture is rift with soul. Consider the numerous turns of speech, e.g., 'we are soul mates', or 'she is an old soul,' or 'that music touched my soul' and so on. As defined colloquially by Kaufman, soul is 'a distinct nonmaterial kind of reality taken to be the very heart of our humanness (1993, p. 107).' Besides being used to represent that which is most true and just about the self ('touched my soul'), relationships ('soul mates'), another incarnation ('old soul'), soul can also be used to represent transcendence. According to Kaufman: 'if we see humans as souls then we are most interested in their eternal destiny, their place in the spiritual world, their relationship with God or to God (1993, p. 78).' Indeed, the Jungian scholar, James Hillman (1996), following Plato's Myth of Er, suggests that soul could be linked with a daemon, who helps to guide it on its way to the realization of a profane truth that represents its sacred destiny. In this sense, the destiny is meant to reflect a moral good to which the soul can best devote itself; a good that is reflective of its 'true calling,' its 'defining image.'

Philosophical precedent (e.g., Plato's Apology and Descartes' Meditations) provided the traditional senses of soul, an internal spiritual source acting as intermediary between the person's self in material existence and the Deity. While acknowledging the more logical arguments for the soul's existence found in Plato's Phaedo, most telling for the present theology are the 
aforementioned pragmatic (cf. James' Pragmatism) 'arguments'. Using soul to selectively refer to those elements of self-functioning that capture the essence of the self, along with identifying what represents the most permanent part of the self, perhaps extending beyond the current self's lifetime, can be quite useful in discourse relating to everyday life, and more spiritual contexts.

However, by adding soul, self needs to be re-conceptualized in relation to it. Given traditional notions of soul, it is an entity already present in the human being from birth; however, one could argue that not until cognitive developmentalist Jean Piaget's (1967) sensation-reflection split occurs, does it start to become the self's moral compass, a vantage point from which the self can evaluate itself regarding what is most true or moral. However, throughout development soul is less than pure, given inextricable ties to a self that is embodied and in most cases, socially constituted. In short, one needs a self that is structurally and functionally capable of being in interaction with a soul.

Self and soul may achieve more growth benefits in relationship to each other, than either one could alone. Through a divinely guided trajectory of development (cf. Kaufman's 1993, 'cosmic directionality,'), soul is increasingly influenced by the continued evolution (cf. Kaufman's 2004, 'serendipitous creativity') of biological, psychological and social consciousness of self. As a result, moral sensibility (cf. Kaufman's 2004, 'historicity') of soul broadens and deepens, and possibilities for transcendence of self present themselves. Building on work by the material linguistic philosopher Mark Johnson (1987), one can posit that the two contexts of mind and body provide the origins of metaphor, by which radically new meanings are created. What follows is a meditation on how metaphor creates self as material spirit, which can then be used to understand meanings of both soul and self in a transcendent way. Soul may gain as much from its self, as self from its soul; both may gain most within a transcendently united community of material spirits.

It should be clear to the reader by now, that the kind of philosophy being advocated herein this constructive theology of self is best described as a Subsumtive Philosophy: one that subsumes the metaphysical and the physical; the moral and the empirical; the relatively certain and the relatively speculative. It is also a Subsumtive Philosophy applied to this Constructive Theology of Self that is ultimately pragmatic: given the uncertainty of finding incontrovertible empirical evidence relating to the 'soul' at the present time, among other things, it would have to be at least this, if it is anything.

\section{Part IV. Meditation: On the Possible Origins of Metaphor and the Development of Self and Soul}

The 'raw' state of self provides the conditions within which metaphor is born and nurtured. Such conditions include 'the mind' as the action theorist, A.I. Melden (1961) might understand it, as an actual conflation of intention and will related to one another within a context of 'free action'; and the 'body' as 
psychologist Robert Solomon (1977) might understand it, as various sensuous affects, experienced within a particular 'passionate' context of bodily states and movements. Consider as well that bodily sensation can inform the operation of reason (Damasio, 1994), while reason can rationalize the emotions (Richard Shweder, 1991).

As Aristotle in his Poetics claimed, metaphor's genius may lie in revealing the similarity of two dissimilars. Might its inception be within the fundamental dichotomy present within the raw state of the self, with sensation (a pure experience of an event) splitting from reflection (thinking about an experience), as Jean Piaget (1967) has shown? Gradually, through the first year of an infant's life, the arising of the symbolic function (representing something physically absent) further refines metaphor's emergence, and consequent moral and self-individuating action, ultimately guided by the soul.

The workings of metaphor within the state of the material spirit may provide the greatest possibility for spiritual growth of the soul in isolation, if that is the soul's desire. Linguistic philosopher Max Black (1965) argued that metaphor works by providing a framework of one phenomenon's 'commonplaces' through which to view another phenomenon's commonplaces. Thus, because of the framework of the former, certain commonplaces of the latter are emphasized, others de-emphasized. The result is a phenomenon, while having commonalities with both phenomena initially, is radically different. Consider 'the lake is a sapphire', 'the church is a rock', 'the body is a mind', 'the mind is a body'; from these latter two is born self as material spirit. That which serves as a vessel for soul's manifestation, via the spiritual workings of metaphor in relationship to mind and body, is self as material spirit. That which cultivates the epistemic, moral, prudential, etc., essence of human experience in relationship to further development of the self as material spirit, is soul.

It is interesting to consider how the mind-body distinction as captured within self as material spirit may eventually be dissolved as the soul develops spiritually. Imagine the body providing vast impetus for the mind to generate a moral code grounded in 'natural law,' and to continually develop new ethical systems coterminous to the spiritual realm. Think of mind strengthening body by making it more rationally beholden to its own sensuality, and to a bodyethic which transcends it. Reflect on the possibility that given enough time the traditional distinction between mind and body may well dissolve: The body will have become as much a sacred vessel, as the aesthetic is its (the body's) own object, while the mind will have become as much a sensuous poetry, as the ethical is its (the mind's) own workings. The effect of this dissolution may be as important for the development of the soul, as the soul was for the dissolution's initiation.

However, for souls deciding to bind together in communities under guidance of a symbol transcending any individual soul, spiritual growth could be limitless. This could be a local or a universal acceptance of a symbol of a Deity, e.g. Allah, Krishna, Jesus, etc., or of some other symbol, like the Good, the First Principle, etc. Given the unifying and transcending nature of such a 
symbol, the possibilities for spiritual development, and thus any development oriented towards achieving ultimate Good, may be engaged. Including such a symbol confers the benefits of scripture, whether via the Holy Bible, the Quran, the Vedic scriptures, or the benefit of what some consider welldeveloped arguments, found in Plato's Republic or Apology, Descartes' Meditations, Mills' On Liberty, etc.

\section{Epilogue: On Some Additional Philosophical Possibilities}

One of the principal challenges is the soul's unabashed religious grounding and its alleged continuance beyond material existence. Dennett likens the soul to a 'a pathetic bauble to brandish like a lucky charm (1991, p. 430).' He believes it unnecessary to posit a soul to ensure immortality because self as center of narrative gravity will do better given its ability to 'theoretically survive indefinitely many switches of medium, be teleported as readily (in principle) as the evening news, and stored indefinitely as sheer information (p.430).' Even so, these possibilities still beg the question whether any are preferable to an immortal ontological experience of soul. That measurement of soul in this sense has proven intractable does not deter the philosopher M.B. Woodhouse (1990), who suggests its intractability may simply be due to our not having yet developed a way to measure the frequency level of the energy which makes it up; thus, positing the existence of soul may ultimately be compatible with materialist doctrine.

If soul cannot be dismissed easily, certainly not pragmatically and maybe not empirically, then there is the question of whether the concepts of soul, self, and mind, along with the body that they allegedly inhabit, should be referred to interchangeably, or separately. Maintaining a distinction is useful for everyday life, theology in general, and this constructive theology in particular, which claims the emergence of metaphor arising out of a mind-body interactive context, and then within a community context, assisting the soul to create and maintain the self. Because of the directive influence of soul, self becomes a spiritual entity, but of a particular sort. Given the bodily and community contexts within which it arises, it may be best conceived as a socio-material spirit, as opposed to just a material spirit, the central argument with which this paper started. Within a community of care the soul is most likely to guide the self, which in turn enriches and further develops the soul. So, such distinctions serve multiple purposes.

From the perspective of ontogeny, traditionally soul is not thought to arise anew within the context of each material spirit self, but rather to inhabit such a self right from birth; although of course in some cases surely new souls are generated. Such differences may manifest empirically, but how? Regarding self ontogeny, it is a different matter, with each self being freshly created. Community and culture may interact with the bodily constitution of self and soul, affecting in particular ways development of each. 
Ontologically, self and soul appear to have both conscious and unconscious elements, with sensation and reflection processes characterizing each. As sensations are experienced, some are reflected upon and consciously categorized, described and named. Even if they are not reflected upon, they may still be a part ontologically of self and soul. At this point, if they are questioned how they came about, or what their nature is, or for what they will be used, etc., they become available for re-describing.

Considering epistemology, both self and soul can be pluralistically explained. When one explains a described event with a cause, one is identifying something that occurred temporally prior to the event, and thus the event is re-described as an effect; or it could be explained with a reason - or justification - that serves to connect the initial event re-described as a means to an end. These rhetorical acts serve to develop the meaning of self and/or soul, especially what the causes or purposes are, and thus ultimately what either one is or will become. In addition, reasons can be causes, and causes reasons. For example, by virtue of the cause of what either one is, it serves as a reason for what either one will become: a dysfunctional dopaminergic biochemical system causes one to become a person with schizophrenia, and thus in turn serves as a reason, i.e., justification, for that outcome.

Based in part on Kaufman's recommendations, this Subsumtive Philosophy of a Constructive Theology of Self incorporates ongoing scholarly developments across the humanities, natural and social sciences. Most importantly, it rests on a continued critical engagement of scriptural sources in relationship to advances made in empirical, logical, and moral thought: empirical, grounded in the sciences; logical, grounded in what is sensibly, syntactically, semantically - and by the laws of logical inference - possible; moral, grounded in what should be the case - pragmatically relevant to the moral principles of the sanctity of human freedom and of human life.

\section{Selected References}

Black, M. (1962). Models and metaphors. Ithaca: Cornell University Press.

Cohler, B.J. (1983). 'Personal narrative and life course.' In: P. Baltes \& O. Brim, Jr. (Eds.) Life-span development and behavior Volume 3, 205-230, New York: Academic Press.

Comer, R. (2013). Fundamentals of abnormal psychology. New York: Worth.

Damasio, A.R. (1994). Descartes' error: Emotion, reason, and the human brain. New York: Random House.

Dennett, D.C. (1991). Consciousness explained. New York: Penguin.

Derrida, J. (1978). Writing and difference. Chicago: The University of Chicago Press.

Fiske, D.W. (1971). Measuring the concepts of personality. Chicago: Aldine.

Freud, S. ([1923] 1960). The ego and the id. New York: W.W. Norton.

Gergen, K. J. (1988). 'If persons are texts.' In S.B. Messer, L.A. Sass, \& R.L Woolfolk, (Eds.) Hermeneutics and psychological theory, 28-51, New Brunswisck: Rutgers University Press..

Hillman, J. (1996). The soul's code: In search of character and calling. New York: Warner. 
Johnson, M. (1987). The body in the mind: The bodily basis of meaning, imagination, and reason. Chicago: University of Chicago Press.

Jung, C.G. (1957). The undiscovered self. New York: Little, Brown, \& Co.

Kaufman, G.D. (2004). In the beginning . . creativity. Minneapolis: Fortress Press

Kaufman, G.D. (1993). In face of mystery: A constructive theology. Cambridge, Mass: Harvard University Press.

Kircher, T., and David, A. (2003). The self in neuroscience and psychiatry. Cambridge: Cambridge University Press.

Marcus, H., \& Nurius, P. (1986). 'Possible selves.' American Psychologist. 41(9): 954-969.

Maslow, A.H. (1968). Toward a psychology of being. New York: Van Nostrand Reinhold.

Mead, G.H. (1934). Mind, self, and society. Chicago: University of Chicago Press.

Melden, A.I. (1961). Free Action. New York: Humanities Press.

McAdams, D.P. (1997). Stories we live by: Personal myths and the making of self. New York: William Morrow.

Parry, A., \& Doan, R.E. (1994). Story re-visions: Narrative therapy in the postmodern world. New York: Guilford Press.

Piaget, J. (1967). Six psychological studies. New York: Random House.

Rogers, C. (1961). On becoming a person. Boston: Houghton Mifflin.

Shweder, R. A. (1991). Thinking through cultures: Expeditions in cultural psychology. Cambridge, Mass. Harvard University Press.

Solomon, R.C. (1977). The Passions. Garden City, NY: Anchor.

Swann, W.B. Jr. (1983). 'Self-verification: Bringing social reality into harmony with the self.' In: J.Suls \& A.G. Greenwald's (Eds.), Psychological perspectives on the self (Vol. 2), 33-36,_Hillsdale, N.J.: Lawrence Erlbaum.

Woodhouse, M.B. (1990). A preface to philosophy. Belmont, CA: Wadsworth. 
